DOI: $10.17957 / \mathrm{IJAB} / 15.1792$

http://www.fspublishers.org

\title{
Improved Cold Tolerance is Associated with Altered Cell Wall Composition in Pre-Planted Tobacco
}

\author{
Ming Fang ${ }^{1}$, Huina Zhou ${ }^{2}$, Zhihui Cao ${ }^{1}$, Yongjun $\mathrm{Liu}^{3}$, Jun $\mathrm{Li}^{1}$, Yansong Xiao ${ }^{1}$, Peijian $\mathrm{Cao}^{2}$, Jianlin $\mathrm{Hou}^{1}$, Hu Yuan ${ }^{1}$ \\ and Qiansi Chen ${ }^{2 *}$ \\ ${ }^{1}$ Chenzhou Company of Hunan Tobacco Company, Chenzhou 423000, P. R. China \\ ${ }^{2}$ Zhengzhou Tobacco Research Institute of CNTC, Zhengzhou 450001, P. R. China \\ ${ }^{3}$ Hunan Tobacco Research Institute, Changsha 410000, P. R. China \\ "For correspondence: chen_qiansi@163.com \\ Received 06 October 2020; Accepted 16 March 2021; Published 10 May 2021
}

\begin{abstract}
Tobacco seedlings produced by floating system are susceptible to cold injury. This problem can be solved by pre-planting technique. However, little is known about the mechanism underlying the improved cold tolerance in pre-planting tobacco. To investigate it, the cytological features of the leaf and root cells from floating and pre-planting tobacco were studied. Obvious cold injury and rupture of cell membrane system were observed in the cells from floating tobacco under cold stress conditions but very little in the cells from pre-planting tobacco. The cell wall in cells from pre-planting tobacco was thicker than in floating tobacco before cold stress. The cell wall was higher in cellulose and pectin contents in pre-planting tobacco than in floating tobacco before and after cold stress. These results suggest that pre-planting technique facilitates the accumulation of cell wall compositions-cellulose and pectin in pre-planting plants to prevent the cold injury, and possibly attenuates the negative effect of flooding stress on cell wall composition. (C) 2021 Friends Science Publishers
\end{abstract}

Keywords: Pre-planting tobacco; Flooding tobacco; Cold stress; Ultrastructure; Cell wall

\section{Introduction}

Tobacco (Nicotiana tabacum L.) is cultivated worldwide as an important economic crop (Xu et al. 2019). In China, tobacco is mainly planted in Hunan, Yunnan and Guangxi provinces for commercial purposes (Xiao et al. 2007; Liu et al. 2020). These provinces are located in southern China, where the large-scale floating system is widely used for tobacco seeding due to less cost, improved quality and yield of its products (Zhou et al. 2019). However, there are some problems associated with the floating system, such as prolonged seedling period, delayed root development, decreased disease resistance, and enhanced cold sensitivity (Zhou et al. 2019). For example, the temperature is low, and sunlight is sparse in Hunan province when the tobacco seedlings are transplanted to the fields in March or April (Xu et al. 2019). Most tobacco seedlings produced by floating system would die from severe cold damage (Xu et al. 2019). Nevertheless, pre-planting technique helps the growth of floating seedlings and increases their survival rate under cold stress (Fang 2015). It is known that pre-planting treatment causes lots of physiological changes, such as ion and osmotic homeostasis and photosynthesis, thereby affecting plant growth (Gao and Zhou 2001). The mechanisms underlying the decreased cold injury through pre-planting needs to be further investigated.

Cold stress at seedling stage seriously affects tobacco growth and production ( $\mathrm{Hu}$ et al. 2016). Plants normally adapt to low temperature environments through cold acclimation whereas the freezing tolerance can be achieved by low non-freezing temperature (Chen et al. 2014). During cold acclimation, a lot of biochemical and molecular cell biological changes would occur. Lipid composition, sugar and soluble protein contents, phytohormone levels are all changed during plant adaption to cold (Welin et al. 1995; Chen et al. 2014). Along with it, many cold responsive and regulatory genes associated with improved freezing tolerance are activated, such as the cold-inducible transcription factor genes and the cascade genes mediated by the well-known C-repeat (CRT)-binding factor/dehydration-responsive element (DRE) binding factor (CBF/DREB) (Chinnusamy et al. 2003; Tian et al. 2013; Hu et al. 2016).

Cold stress can damage or rupture cell membrane including both plasma membrane and membrane of cellular organelles, which are the fundamental mechanism of plant cold injury (Seo et al. 2010; Chen et al. 2014). In addition, cell wall plays a role in plant response to cold stress

To cite this paper: Fang M, H Zhou, Z Cao, Y Liu, J Li, Y Xiao, P Cao, J Hou, H Yuan, Q Chen (2021). Improved cold tolerance is associated with altered cell wall composition in pre-planted tobacco. Intl J Agric Biol 25:1303-1310 
(Parrotta et al. 2019). Plant cell wall is mainly composed of cellulose, hemicellulose, lignin, pectin, and proteins (Zhao et al. 2019). In maize, cold stress causes remarkable decrease of pectin level and the enzyme activity associated with it (Bilska-Kos et al. 2018). The cold-tolerant maize has thickened cell wall of leaf cells and changed cell wall sugars (Bilska-Kos et al. 2018). Cold stress increases the expression of cinnamyl alcohol dehydrogenase (CAD) gene leading to the increase of CAD enzyme activity and beta(D)-glucans content in Miscanthus (Parrotta et al. 2019). CAD gene is involved in lignin synthesis and the synthesis of beta-(D)-glucans which are the components of hemicellulose (Carpita et al. 2001; Domon et al. 2013). Silencing an inhibitor of cell wall invertase increases invertase activity and enhances the chilling tolerance in tomato (Xu et al. 2017). In tobacco pollen tubes, cold stress alters the deposition of cellulose, pectin, and callose in cell wall (Parrotta et al. 2019).

In present study, the plant phenotypes were investigated for cold response and the subcellular features of tissues from floating tobacco and pre-planting tobacco. The results indicate that the cell wall structure and composition are possibly involved in different degrees of cold tolerance between floating and pre-planting tobacco under cold treatment.

\section{Materials and Methods}

\section{Plant culture}

The seed of Yunyan 87, the most widely planted cultivars in China (Jiao et al. 2010), was sown in the holes of floating trays $(55 \mathrm{~cm} \times 35 \mathrm{~cm}, 200$ holes/plate $)$ on the water culture. Half of the germinated seedlings continued to grow in floating trays as the floating group; another half of the germinated seedlings were transplanted to moist nutrient culture as the pre-planting group at 45 days post sowing. All seedlings were grown in greenhouse with the settings of a $16 / 8 \mathrm{~h} \mathrm{light/dark}$ cycle, $25^{\circ} \mathrm{C}$ and $40 \%$ humidity for 15 days.

\section{Cold treatment}

All seedlings were grown in greenhouse with the above growth conditions for 10 days. Then, the condition was switched to $12 / 12 \mathrm{~h}$ light $\left(4^{\circ} \mathrm{C}\right) /$ dark $\left(0^{\circ} \mathrm{C}\right)$ cycle with $50 \%$ humidity for 5 days. The samples were collected at 0 and 5 days under cold treatment. The cold treatments were biologically repeated three times and the results from one replicate were shown.

\section{Microscopic structures analysis}

The ultrastructure of tobacco leaf and root cells was studied by transmission electron microscopy. The leaves and the elongation zone of roots were sampled at 0 and 5 days after cold treatment. The tobacco tissues were cut into $1 \times 2 \mathrm{~mm}$ pieces which were immediately fixed in $2.5 \%(\mathrm{w} / \mathrm{v})$ glutaraldehyde in $0.1 \mathrm{M}$ phosphate buffer solution (PBS) (pH 7.2) at $4^{\circ} \mathrm{C}$ overnight. The fixed tissues were washed three times in $\mathrm{PBS}$ with each time at room temperature $\left(20-25^{\circ} \mathrm{C}\right)$ for $30 \mathrm{~min}$, postfixed for $2 \mathrm{~h}$ in $1 \%$ osmium tetroxide, dehydrated in a graded series of acetone, infiltrated with Spurr resin (SPI, SPI Chem, West Chester, PA, United States) followed by polymerization at $65^{\circ} \mathrm{C}$ for $48 \mathrm{~h}$. The samples were cut into ultrathin sections (60-70 $\mathrm{nm}$ thick), stained with $2 \%$ uranyl acetate, and examined with a Hitachi transmission electron microscope $(\mathrm{H}-7650$, Hitachi, Japan) at $80 \mathrm{kV}$. For each sample, 3 biological replicates were prepared and at least 3 ultrathin sections per replicate were observed under the electron microscope. To quantify the cells exhibiting broken plasma membrane and protoplast shrinkage, 80 mesophyll and cortical cells each in total were observed from four leaf and root for each treatment group. To measure the thickness of cell wall, 16 mesophyll and cortical cells were chosen from four leaf and root respectively of each treatment group where the thickness of cell wall was measured at four spots in each cell.

The tissue samples from tobacco leaves and roots at 0 day under cold stress were fixed in $2.5 \% \mathrm{v} / \mathrm{v}$ glutaraldehyde in PBS (pH 7.2) buffer. The fixed samples were dehydrated, infiltrated and embedded in LR White acrylic resin (Electron Microscopy Sciences, Pennsylvania, U.S.A.). Embedded samples were cut into $0.5 \mu \mathrm{m}$ thick sections, stained with Calcofluor White (Sigma-Aldrich, Missouri, U.S.A.) for $1 \mathrm{~min}$, and viewed under $2 \mathrm{~s}$ of UV exposure by Nikon 80i fluorescence microscope (Nikon, Tokyo, Japan). There were 3 biological replicates for each sample, and at least 3 sections were observed per replicate.

\section{Assays of cell wall composition}

Cellulose, hemicellulose, pectin, and lignin contents from 2 $\mathrm{g}$ powdered leaf or root were analyzed using the kits for their measurement (COMINBIO, Suzhou, China) (Li et al. 2019). The contents of each composition in all the samples were calculated based on the absorbance values at $660 \mathrm{~nm}$ using orcinol monohydrate spectrophotometric method, at $540 \mathrm{~nm}$ using anthrone spectrophotometric method, at 280 $\mathrm{nm}$ using acetyl bromide spectrophotometric method, and at $530 \mathrm{~nm}$ using carbazole spectrophotometric method respectively.

\section{Statistical analysis}

The significant difference between floating and pre-planting tobacco was evaluated using pairwise Student's $t$-test in Excel (Microsoft, http://www.microsoftstore.com) for phenotype comparison, including leaf and root number, root system length, the number of cells with broken plasma membrane and protoplast shrinkage, the thickness of cell wall and the contents of cell wall compositions. 


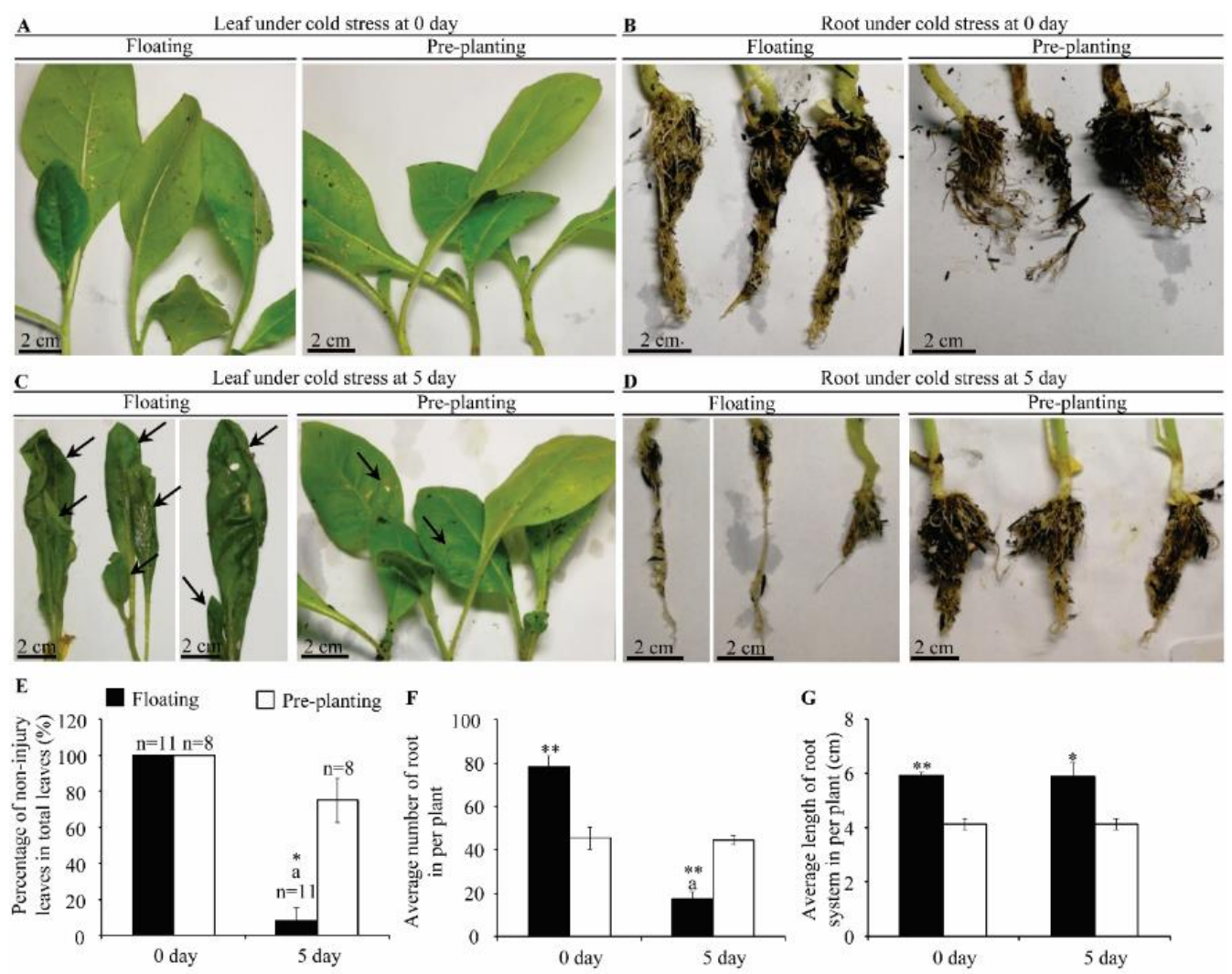

Fig. 1: Leaf and root phenotypes of floating and pre-planting tobacco. Black arrows, cold injury in the leaves. (A, C) Leaf phenotypes in floating and pre-planting tobacco. (B, D) Root phenotypes in floating and pre-planting tobacco. (E, F, G) Percentage of leaves with no cold injury, root number and root length per plant in floating and pre-planting tobacco. Data are presented as means of 11 leaves from 4 floating tobacco and 8 leaves from 4 pre-planting tobacco, all roots, and the root system from 4 tobacco plants respectively \pm standard error (SE). Letter "a" indicates the statistically significant difference between 0 day and 5 day after cold stress at $P<0.01$ in the same tobacco plants. Double asterisks $(* * P<0.01)$ and single asterisk $(* P<0.05)$ indicate the significant difference between floating tobacco and pre-planting tobacco at the same day after cold stress

\section{Results}

\section{Effects on growth}

The leaf and root phenotypes of floating and pre-planting tobacco were compared under low temperature treatment (Fig. 1). At 0 day after cold stress, the leaves from the two groups of plants appeared similar (Fig. 1A); however, the number and length of roots in floating tobacco were significantly more and longer than pre-planting tobacco (Fig. 1B, F, G). At 5 days after cold stress, the cold injury symptoms were shown in almost all the leaves of floating tobacco but only in some leaves of pre-planting tobacco (Fig. 1C); the number of leaves in floating tobacco without visible damage was significantly less than both in floating tobacco at 0 day after cold stress and in pre-planting tobacco (Fig. 1E). At 5 days after cold stress, the number of roots in floating tobacco was significantly less than both in floating tobacco at 0 day after cold stress and in pre-planting tobacco (Fig. 1D, F). At 5 days after cold stress, the length of roots in floating tobacco was still longer than in pre-planting tobacco (Fig. 1G).

\section{Ultrastructure of mesophyll cells}

The analyzed ultrastructure of mesophyll cells in leaves of both floating and pre-planting tobacco was showed (Fig. 2). At 0 day after cold stress, a few intact chloroplasts and plasma membrane tightly attached by cell wall were observed (Fig. 2A, A-1, A-2). At 5 days after cold stress, the mesophyll cell of floating tobacco showed ruptured plasma membrane, broken chloroplast membrane, and protoplast shrinkage (Fig. 2B, B-3). However, at 5 days after cold stress, the chloroplasts around the cell wall and their membrane remained intact and there was considerable amount of cytoplasmic matrix in pre-planting tobacco (Fig. 2B, B-4). Meanwhile, at 5 days after cold stress, the number of mesophyll cells showing broken plasma membrane in floating tobacco was significantly more than both in floating tobacco at 0 day after cold stress and in pre-planting tobacco (Fig. 2C). At 5 days after cold stress, the number of mesophyll cells showing broken plasma membrane in pre-planting tobacco was also more than in pre-planting tobacco at 0 day after cold stress (Fig. 2C). 


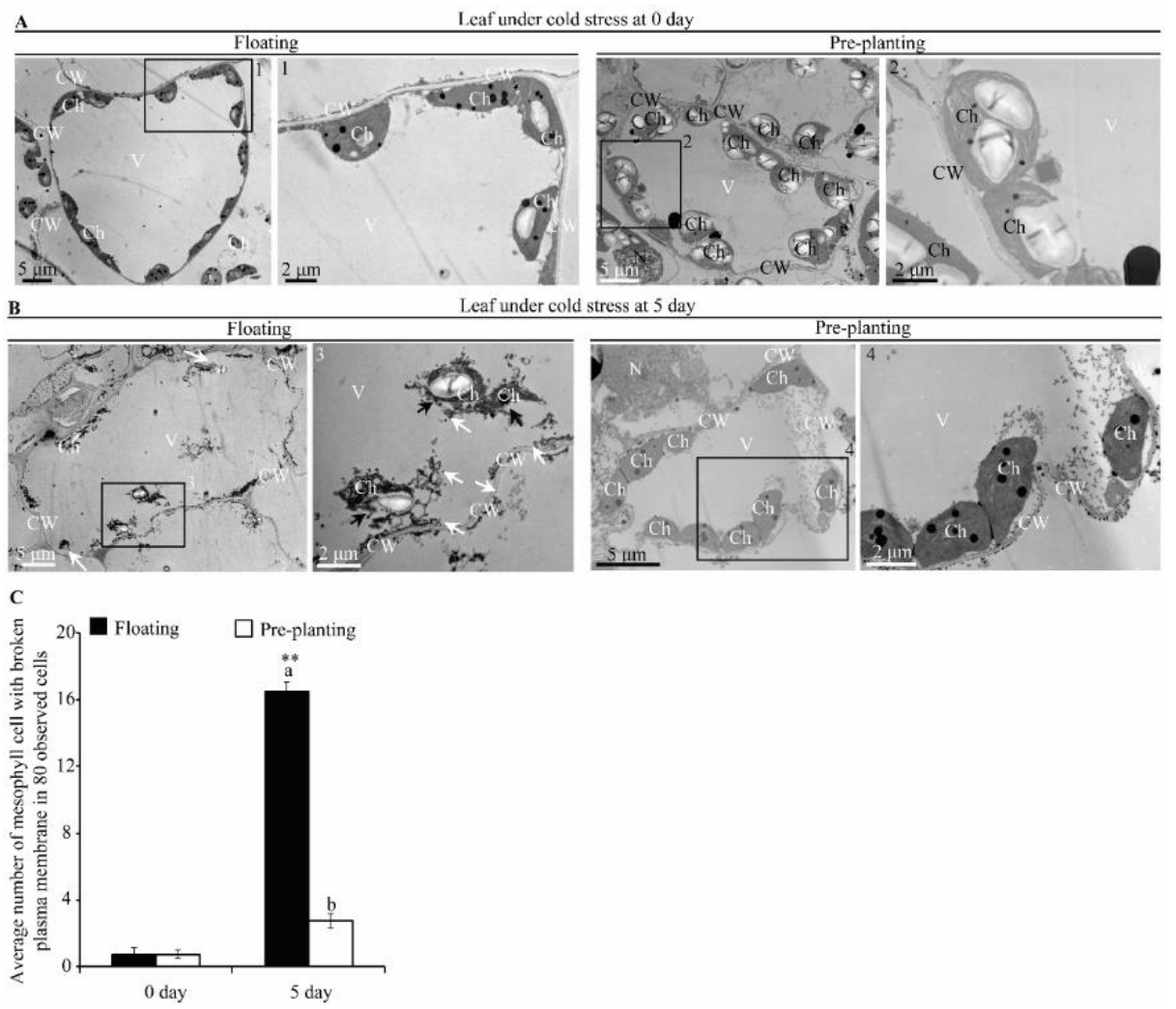

Fig. 2: Many mesophyll cells with broken plasma membrane in leaves of floating tobacco. CW, cell wall; Ch, chloroplast; V, vacuole; N, nucleus; white arrows, rupture of plasma membrane; black arrows, rupture of chloroplast membrane. The 1, 2, 3 and 4 black rectangles representing the enlarged images at their right sides. (A) The normal ultrastructure of mesophyll cells in floating and pre-planting tobacco. (B) The damaged mesophyll cell of floating tobacco comparing with the normal mesophyll cell in pre-planting tobacco. (C) Number of mesophyll cells with broken plasma membrane in floating and pre-planting tobacco. Data represent means of 80 observed cells from 4 plants \pm SE. Letters "a" and "b" indicate the statistically significant difference between 0 and 5 days after cold stress at $P<$ 0.01 and $P<0.05$ in the same tobacco. Double asterisks $(* * P<0.01)$ and single asterisk $(* P<0.05)$ stand for the significant difference between floating and pre-planting tobacco at the same day under cold stress

\section{Ultrastructure of cortical cells}

The ultrastructure of cortical cell in root of floating and preplanting tobacco under cold stress showed different ultrastructure changes between them (Fig. 3). At 0 day after cold stress, the cytosol with nucleus and mitochondrion around the cell wall was condensed in the cortical cells of the roots from both floating tobacco and pre-planting tobacco (Fig. 3A, A-1, A-2). At 5 days after cold stress, the protoplast shrinkage and some rupture of plasma membrane were observed in the cortical cells of floating tobacco (Fig. 3B, B-3), but the cortical cells of pre-planting tobacco had intact nuclei and considerable amount of cytoplasmic matrix around cell wall (Fig. 3B, B-4). Meanwhile, at 5 days after cold stress, there were significantly more cortical cells with protoplast shrinkage in floating tobacco than both in floating tobacco at 0 day after cold stress and in pre-planting tobacco (Fig. 3C). At 5 day after cold stress, the number of cortical cells showing protoplast shrinkage in pre-planting tobacco was also more than in pre-planting tobacco at 0 day after cold stress (Fig. 3C).

\section{Changes of cell wall compositions}

The cell wall features of mesophyll and cortical cells in both the leaf and root samples were analyzed in ultrastructural level (Fig. 4). At 0 day under cold stress, the cell wall electron-density of both types of cells in floating tobacco was higher than in pre-planting tobacco (Fig. 4A, B), and their cell walls in floating tobacco were also significantly thinner than in pre-planting tobacco (Fig. 4C, D).

To further investigate the cell wall difference between floating and pre-planting tobacco, the transverse semi-thin sections of leaf and root were stained by calcofluor and observed under a fluorescence microscope. Results showed that the calcofluor fluorescence intensity of cell wall was weaker in both mesophyll and cortical cells from floating tobacco than of the cells from pre-planting tobacco at 0 day under stress (Fig. 5A, B). The contents of cellulose and pectin in leaf and root samples from floating tobacco were significantly less than from pre-planting tobacco (Fig. 5C); while the contents of hemicellulose and lignin in the tested samples did not show any significant difference between 

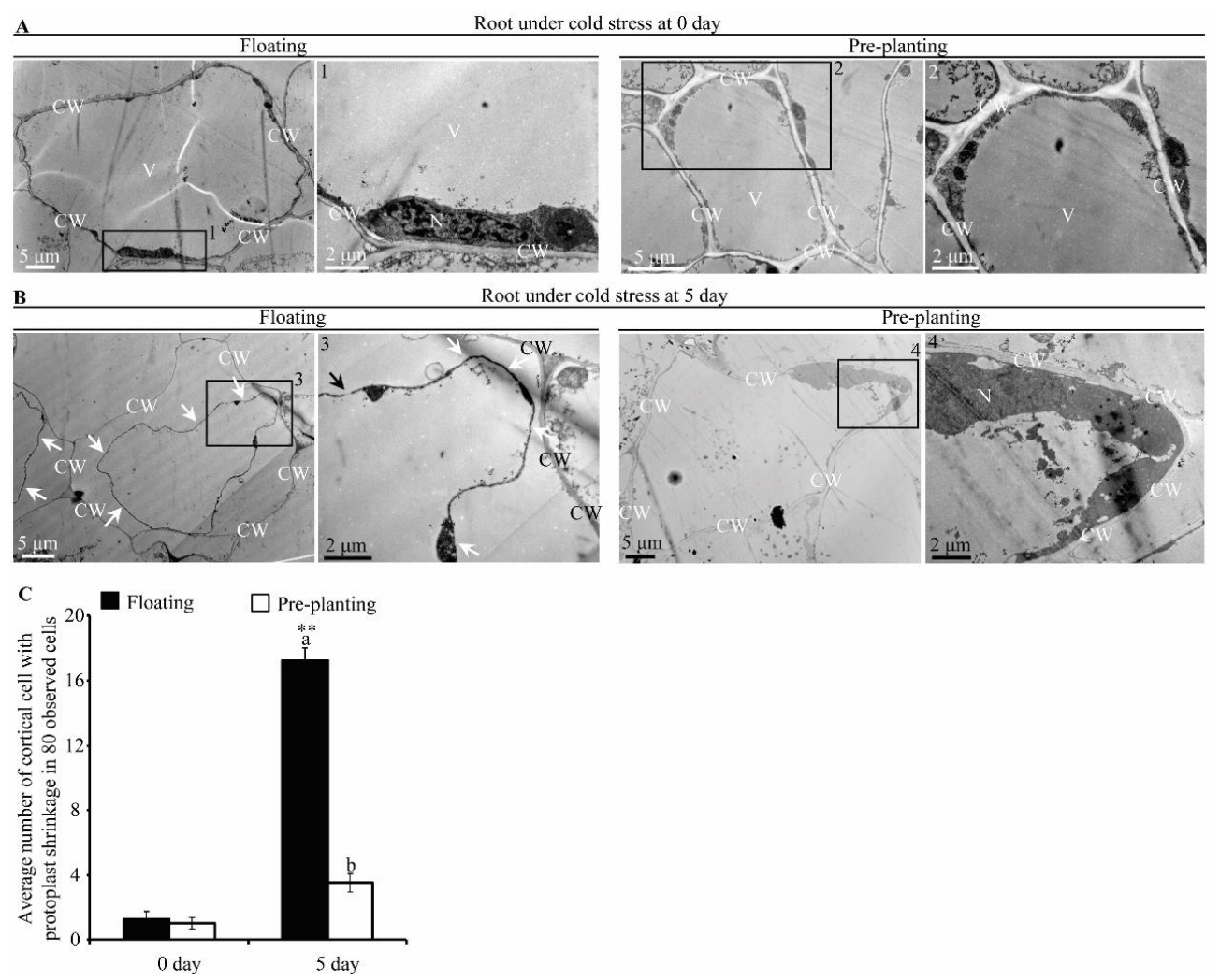

Fig. 3: Many cortical cells with protoplast shrinkage in roots of floating tobacco. CW, cell wall; V, vacuole; N, nucleus; white arrows, protoplast shrinkage; black arrows, rupture of plasma membrane. The 1,2,3 and 4 black rectangles representing the enlarged images at right sides. (A) The normal ultrastructure of cortical cells in floating and pre-planting tobacco. (B) The damaged cortical cell in floating tobacco comparing with the normal cortical cell in pre-planting tobacco. (C) Number of cortical cells with protoplast shrinkage in floating and pre-planting tobacco. Data represent means of 80 observed cells from 4 plants \pm SE. Letters "a" and "b" indicate the statistically significant difference between 0 and 5 days after cold stress with $P<0.01$ and $P<0.05$ in the same tobacco. Double asterisks (** $P<0.01$ ) stand for the significant difference between floating and pre-planting tobacco at the same day under cold stress

floating and pre-planting tobacco (Fig. 5C). In addition, the contents of cellulose, hemicellulose, pectin and lignin in floating tobacco and pre-planting tobacco were not different between at 0 day after cold stress and at 5 days after cold stress (Fig. 5C; Fig. S1). At 5 day under cold stress, the contents of cellulose and pectin in floating tobacco and pre-planting tobacco were similar to the contents in tobaccos at 0 day under cold stress (Fig. 5C; Fig. S1).

\section{Discussion}

Cell membrane rupture caused by various factors often leads to plant injury (Chen et al. 2014). For example, freezing stress-induced membrane rupture occurs due to the extreme dehydration of extracellular materials, which, leads to the increase of electrolyte leakage in plant tissues (Kaye et al. 1998). The electrolyte leakage is slightly lowered by heterologous expression of two cold-acclimation proteins in transgenic tobacco plants under cold stress (Kaye et al. 1998). Low temperature severely affects tobacco growth (Hu et al. 2016). The rupture of cell membrane is the main underlying cause for plant cold injury (Chen et al. 2014). In present study, the rupture of plasma and chloroplast membrane was observed in leaf and root cells of floating tobacco but not in the cells from the pre-planting tobaccos at 5 days under cold stress (Fig. 2B, 2C, 3B, 3C). These ultrastructure changes indicated clear tissue injury in floating tobacco. The pre-planting tobacco plants had better cold tolerance based on the intact cell membrane system under cold stress.

Plant cell wall serves as the first barrier against cold stress (Parrotta et al. 2019) and not all the cell wall compositions are increased for cold-tolerance in plants $\mathrm{Xu}$ et al. 2020), the thickened cell wall and increased accumulation of cell wall components are commonly considered as one of the main mechanisms in plant adaptation to abiotic stress (Ployet et al. 2018). It is shown that the leaf cells of cold-tolerant maize have increased thickness of cell wall to prevent the chilling injury (BilskaKos et al. 2018). The increased accumulation of cellulose or pectin can modulate cell wall rigidity to prevent freezing-caused cell damage (Le et al. 2015; Ployet et al. 2018). Cell wall modification is associated with the 
$\underline{\mathrm{A}}$

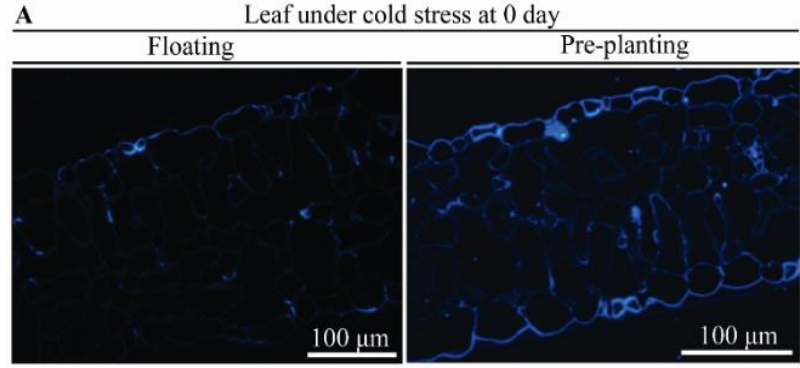

$\underline{\text { B }}$

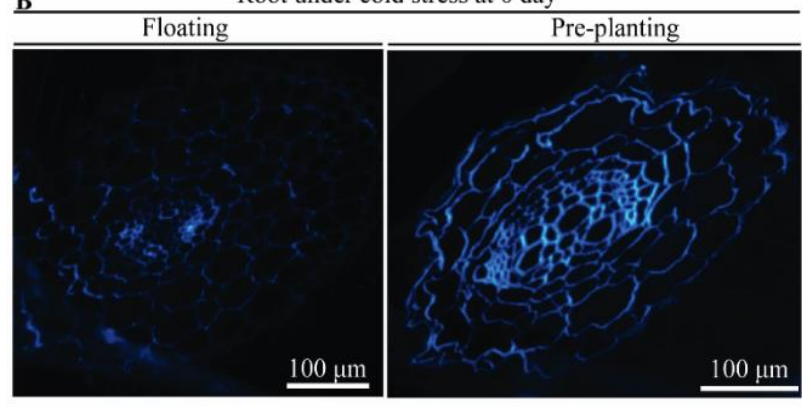

$\underline{C}$

Tobacco under cold stress at 0 day
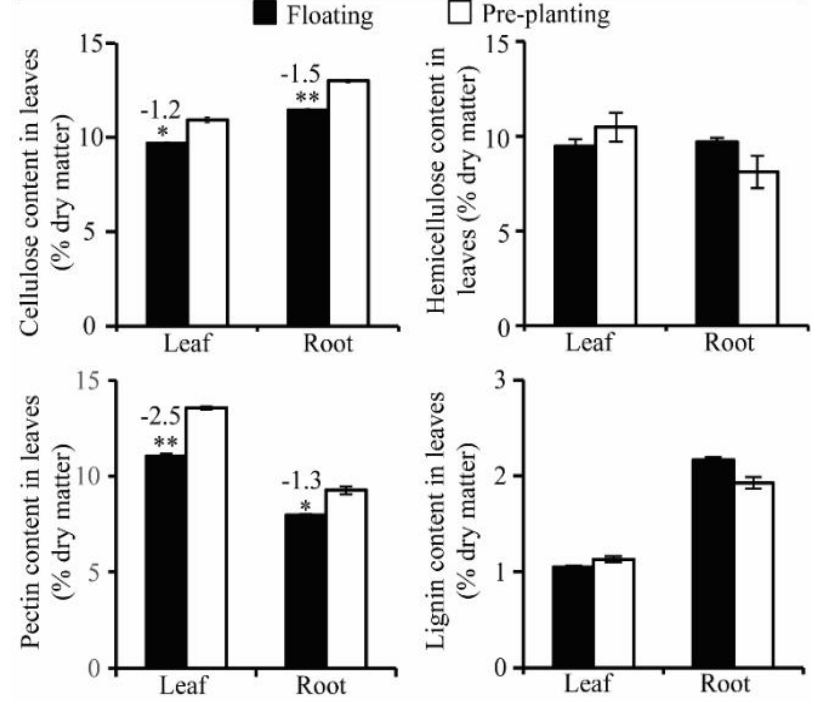

Fig. 5: Less cell wall compositions in floating tobacco than preplanting tobacco. $(\mathbf{A}, \mathbf{B})$ The intensity of calcofluor fluorescence (bright blue) in floating and pre-planting tobacco. (C) The contents of cellulose, hemicellulose, pectin, and lignin in floating and pre-planting tobacco ( $\%$ dry matter) $(\mathrm{n}=3)$. Data represent means from at least 5-10 tobacco plants \pm SE. Double asterisks (** $P<0.01)$ and single asterisk $(* P<0.05)$ stand for the significant difference between floating and pre-planting tobacco

freezing tolerance of pea (Lucau-Danila et al. 2012). Normal cell wall under transmission electron microscope was shown as the layer of structure with low electrondensity, but the cell wall broken by biotic stress was reported to have high electron-density because of the deposition of osmiophilic material in cell wall (Cao et al. 2020). These results from the present study showed slightly thicker cell wall in the leaf mesophyll and root cortical cells
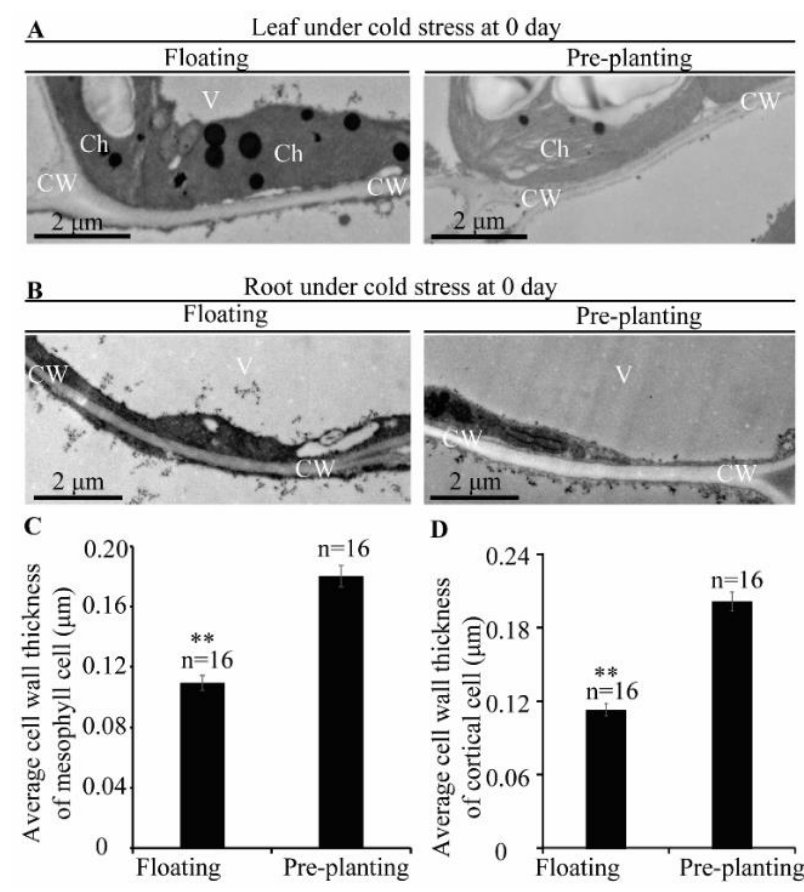

Fig. 4: The high electron-density of thin cell wall in floating tobacco. CW, cell wall; $\mathrm{Ch}$, chloroplast; V, vacuole. (A, B) The higher electron-density of cell wall in floating tobacco than preplanting tobacco. (C, D) The thinner cell wall of floating tobacco than pre-planting tobacco. Data represent means of 16 cells from 4 plants \pm SE. Double asterisks (** $P<0.01$ ) stand for the significant difference between floating tobacco and pre-planting tobacco

from pre-planting tobacco than cells from floating tobacco before cold stress (Fig. 4). In the meantime, Calcofluor specifically staining glucans such as cellulose (Haigler et al. 1980), the contents of cell wall compositions including cellulose and pectin in pre-planting tobacco were significantly higher than in floating tobaccos before and after cold stress (Fig. 5; Supplementary Fig. 1). Thus, cell wall composition and thickness may attribute to difference in cold tolerance between floating and pre-planting tobacco.

It is important to consider the effects of flooding stress when a floating system is used for cultivation. Flooding causes hypoxia which leads to deleterious effects on the roots of soybean and wheat where root elongation and lateral root development are suppressed (Le et al. 2015). Flooding also causes the hyponastic movement of leaf due to the remodeling of cell wall of leaf cells, regulated by a transcription factor affecting the expression of expansin and endo- $\beta$-transglucosylases/hydrolases (Rauf et al. 2013). Flooding also causes the down-regulation of cellulosic synthesis related genes in soybean roots and gray polar (Nanjo et al. 2011). In addition, flooding induces the degradation of cell wall polysaccharide and reduction of pectin content in maize and azuki bean seedlings (Vitorino et al. 2001; Ooume et al. 2009). The roots and hypocotyls of soybean seedlings exhibit decreased lignin deposition, 
polysaccharides cross-linking, and protein modification within cell wall under flooding (Komatsu et al. 2010). In this study, the tobacco seedlings grew on water cultures for 25 days (Zhou et al. 2019). Thus, their roots suffered flooding stress before tobacco seedlings were transplanted to the fields (Zhang et al. 2016). At 0 and 5 days under cold stress, the decreased contents of cell wall compositions including cellulose and pectin were also observed in root and leaf of floating tobaccos in comparison with preplanting tobaccos (Fig. 5; Fig. S1). These evidences suggest that the floating treatment reduces the cell wall compositions in floating tobaccos which leads to higher cold-sensitivity. In other words, pre-planting eliminates the flooding stress and has relatively higher accumulation of cell wall compositions-cellulose and pectin that improves the tolerance to cold treatment.

\section{Conclusion}

In conclusion, the floating tobacco plants suffered cold injury characterized by the rupture of cell membrane system possibly because the flooding induced the decrease of cell wall compositions. Furthermore, the pre-planting tobacco plants, which suffered less flooding stress because of preplanting treatment, maintained the cell wall integrity and cell wall composition contents to mediate cold tolerance. However, cold tolerance is considered to be a quantitative trait (Chen et al. 2014). The cold-resistance involving cell wall in pre-planting tobacco will be further investigated through transgenic tobacco with modified expression of cell wall related genes responding to cold stress.

\section{Acknowledgements}

This study was supported by a grant (No. CZYC2019JS03) from the Chenzhou Company of Hunan Tobacco Company.

\section{Author Contributions}

QC and MF designed the project. MF, QC, HZ, ZC, Y L, $\mathrm{JL}, \mathrm{YX}, \mathrm{PC}, \mathrm{JH}, \mathrm{HY}$ conducted the experiment and analyzed the data. QC and MF wrote the manuscript. QC and $\mathrm{HZ}$ reviewed and edited the manuscript.

\section{Conflict of Interest}

The authors have declared no conflict of interest.

\section{Data Availability}

All data in the studies are available upon reasonable request.

\section{Ethics Approval}

Not applicable.

\section{References}

Bilska-Kos A, P Panek, A Szulc-Glaz, P Ochodzki, A Cislo, J Zebrowski (2018). Chilling-induced physiological, anatomical and biochemical responses in the leaves of Miscanthus x giganteus and maize (Zea mays L.). J Plant Physiol 228:178-188

Cao J, C Chu, M Zhang, L He, L Qin, X Li, M Yuan (2020). Different cell wall-degradation ability leads to tissue-specificity between Xanthomonas oryzae pv. oryzae and Xanthomonas oryzae pv. oryzicola. Pathogens 9; Article 187

Carpita NC, M Defernez, K Findlay, B Wells, DA Shoue, G Catchpole, RH Wilson, MC McCann (2001). Cell wall architecture of the elongating maize coleoptile. Plant Physiol 127:551-565

Chen L, H Xiang, Y Miao, L Zhang, Z Guo, X Zhao, J Lin, T Li (2014). An overview of cold resistance in plants. J Agron Crop Sci 200:237-245

Chinnusamy V, M Ohta, S Kanrar, BH Lee, X Hong, M Agarwal, J Zhu (2003). ICE1: A regulator of cold-induced transcriptome and freezing tolerance in Arabidopsis. Genes Dev 17:1043-1054

Domon JM, L Baldwin, S Acket, E Caudeville, S Arnoult, H Zub, F Gillet, I Lejeune-Henaut, M Brancourt-Hulmel, J Pelloux, C Rayon (2013). Cell wall compositional modifications of Miscanthus ecotypes in response to cold acclimation. Phytochemistry 85:51-61

Fang T (2015). Study on flue-cured tobacco two section type floating system. J Anhui Agric Sci 43:47-48

Gao Z, B Zhou (2001). Improvement of tobacco tray seedling technology. Tob Sci Technol 3:43-44

Haigler C, R Brown, M Benziman (1980). Calcofluor white ST alters the in Vivo assembly of cellulose microfibrils. Science 210:903-906

Hu R, X Zhu, S Xiang, Y Zhan, M Zhu, H Yin, Q Zhou, L Zhu, X Zhang, Z Liu (2016). Comparative transcriptome analysis revealed the genotype specific cold response mechanism in tobacco. Biochem Biophys Res Commun 469:535-541

Jiao F, B Xiao, L Yong, Y Zhang, Y Hai, L Xiu (2010). Breeding and characteristics of Yunyan203, a new variety of flue-cured tobacco. Southwest China J Agric Sci 23:625-629

Kaye C, L Neven, A Hofig, Q Li, D Haskell, C Guy (1998). Characterization of a gene for spinach CAP160 and expression of two spinach cold-acclimation proteins in tobacco. Plant Physiol 116:1367-1377

Komatsu S, Y Kobayashi, K Nishizawa, Y Nanjo, K Furukawa (2010). Comparative proteomics analysis of differentially expressed proteins in soybean cell wall during flooding stress. Amino Acids 39:1435-1449

Le GH, F Philippe, JM Domon, F Gillet, J Pelloux, C Rayon (2015). Cell wall metabolism in response to abiotic stress. Plants 4:112-166

Li T, Q Wu, X Duan, Z Yun, Y Jiang (2019). Proteomic and transcriptomic analysis to unravel the influence of high temperature on banana fruit during postharvest storage. Funct Integr Genomics 19:467-486

Liu P, J Luo, Q Zheng, Q Chen, N Zhai, S Xu, Y Xu, L Jin, G Xu, X Lu, G Xu, G Wang, J Shao, H Xu, P Cao, H Zhou, X Wang (2020). Integrating transcriptome and metabolome reveals molecular networks involved in genetic and environmental variation in tobacco. DNA Res 27:1-16

Lucau-Danila A, C Toitot, E Goulas, AS Blervacq, D Hot, N Bahrman, H Sellier, I Lejeune-Henaut, B Delbreil (2012). Transcriptome analysis in pea allows to distinguish chilling and acclimation mechanisms. Plant Physiol Biochem 58:236-244

Nanjo Y, K Maruyama, H Yasue, K Yamaguchi-Shinozaki, K Shinozaki, S Komatsu (2011). Transcriptional responses to flooding stress in roots including hypocotyl of soybean seedlings. Plant Mol Biol $77: 129-144$

Ooume K, Y Inoue, K Soga, K Wakabayashi, S Fujii, R Yamamoto, T Hoson (2009). Cellular basis of growth suppression by submergence in azuki bean epicotyls. Ann Bot 103:325-332

Parrotta LG, C Faleri, G Guerriero, G Cai (2019). Cold stress affects cell wall deposition and growth pattern in tobacco pollen tubes. Plant $\mathrm{Sci}$ 283:329-342 
Ployet R, M Soler, V Carocha, N Ladouce, A Alves, JC Rodrigues, L Harvengt, C Marque, C Teulieres, J Grima-Pettenati, F Mounet (2018). Long cold exposure induces transcriptional and biochemical remodelling of xylem secondary cell wall in Eucalyptus. Tree Physiol 38:409-422

Rauf M, M Arif, J Fisahn, G Xue, S Balazadeh, B Mueller-Roeber (2013). NAC transcription factor speedy hyponastic growth regulates floodinginduced leaf movement in Arabidopsis. Plant Cell 25:4941-4955

Seo PJ, MJ Kim, JY Park, SY Kim, J Jeon, YH Lee, J Kim, CM Park (2010). Cold activation of a plasma membrane-tethered NAC transcription factor induces a pathogen resistance response in Arabidopsis. Plant J 61:661-671

Tian D, X Pan, Y Yu, W Wang, F Zhang, Y Ge, X Shen, F Shen, X Liu (2013). De novo characterization of the Anthurium transcriptome and analysis of its digital gene expression under cold stress. BMC Genomics 14; Article 827

Vitorino PG, JD Alves, PC Magalhaes, MM Magalhaes, LCO Lima, LEMD Oliveira (2001). Flooding tolerance and cell wall alterations in maize mesocotyl during hypoxia. Pesq Agrop Bras 36:1027-1035

Welin BV, A Olson, ET Palva (1995). Structure and organization of two closely related low-temperature-induced $\mathrm{Dhn} / \mathrm{Lea} / \mathrm{Rab}$-like genes in Arabidopsis thaliana L. Heynh. Plant Mol Biol 29:391-395
Xiao H, K Lu, C Zhang, W Huang (2007). Study on tobacco plant region in Hunan base on GIS technology. J Hunan Agric Univ 33:427-430

Xu J, Q Chen, P Liu, W Jia, Z Chen, Z Xu (2019). Integration of mRNA and miRNA analysis reveals the molecular mechanism underlying salt and alkali stress tolerance in tobacco. Intl J Mol Sci 20:23912408

Xu XX, Q Hu, HN Yang, Y Jin (2017). The roles of call wall invertase inhibitor in regulating chilling tolerance in tomato. BMC Plant Biol 17; Article 195

Xu Y, D Hu, X Hou, J Shen, J Liu, X Cen, J Fu, X Li, H Hu, L Xiong (2020) OsTMF attenuates cold tolerance by affecting cell wall properties in rice. New Phytol 2:498-512

Zhang X, H Lin, H Hu, X Hu, L Hu (2016). Gamma-aminobutyric acid mediates nicotine biosynthesis in tobacco under flooding stress. Plant Divers 38:53-58

Zhao Y, Y Man, J Wen, Y Guo, J Lin (2019). Advances in Imaging Plant Cell Walls. Trends Plant Sci 24:867-878

Zhou L, M Ding, Y Zhang, Y Li, X Shi, Z Zhou, J Zhou, Q Li (2019). PrePlanting technique promoted tobacco root growth due to differentially expressed functional proteins. Intl $J$ Agric Biol 22:979-984 